Burton, T., McKelvey, S., Stewart, D.C., Armstrong, J.D., and Metcalfe, N.B. (2013) Early maternal experience shapes offspring performance in the wild. Ecology, 94 (3). pp. 618-626. ISSN 0012-9658

Copyright (C) 2013 Ecological Society of America

A copy can be downloaded for personal non-commercial research or study, without prior permission or charge

The content must not be changed in any way or reproduced in any format or medium without the formal permission of the copyright holder(s)

When referring to this work, full bibliographic details must be given

http://eprints.gla.ac.uk/79516/

Deposited on: 13 May 2013

Enlighten - Research publications by members of the University of Glasgow http://eprints.gla.ac.uk 


\title{
Early maternal experience shapes offspring performance in the wild
}

\author{
Tim Burton, ${ }^{1,4}$ S. McKelvey, ${ }^{2}$ D. C. Stewart,${ }^{3}$ J. D. Armstrong, ${ }^{3}$ and N. B. Metcalfe ${ }^{1}$ \\ ${ }^{1}$ Institute of Biodiversity, Animal Health and Comparative Medicine, College of Medical, Veterinary and Life Sciences, \\ Graham Kerr Building, University of Glasgow G12 $8 Q Q$ United Kingdom \\ ${ }^{2}$ Conon District Salmon Fishery Board, Aultgowrie Farmhouse, Aultgowrie, By Muir of Ord, Ross-Shire IV6 $7 X A$ United Kingdom \\ ${ }^{3}$ Marine Scotland Science, Freshwater Laboratory, Faskally, Pitlochry, Perthshire PH16 5 LB United Kingdom
}

Abstract. Both the environments experienced by a mother as a juvenile and an adult can affect her investment in offspring. However, the implications of these maternal legacies, both juvenile and adult, for offspring fitness in natural populations are unclear. We investigated whether the juvenile growth rate and adult reproductive traits (length, body condition, and reproductive investment at spawning) of female wild Atlantic salmon (Salmo salar) were related to the growth and survival of their offspring. Adult salmon captured on their upstream migration were used to create experimental full-sib clutches of eggs, which were mixed and then placed in artificial nests in a natural stream that lacked salmon due to a migration barrier. Four months later we resampled the stream to obtain family-level estimates of offspring size and survival. Mothers that had grown slowly as juveniles (as determined by scalimetry) but had invested heavily in reproduction (egg production for a given body length) and were in relatively poor body condition (somatic mass for a given body length) at spawning produced the largest eggs. Larger eggs resulted in larger juveniles and higher juvenile survival. However, after controlling for egg size, offspring growth was positively related to maternal juvenile growth rate and reproductive investment. The predictors of offspring survival (i.e., reproductive success) varied with the juvenile growth rate of the mother: If females grew slowly as juveniles, their reproductive success was negatively related to their own body condition. In contrast, the reproductive success of females that grew quickly as juveniles was instead related positively to their own body condition. Our results show that maternal influences on offspring in the wild can be complex, with reproductive success related to the early life performance of the mother, as well as her state at the time of breeding.

Key words: Atlantic salmon; body condition; indirect genetic effects; maternal effects; maternal growth rate; Salmo salar.

\section{INTRODUCTION}

In addition to their genetic contribution, mothers can adjust the phenotypic development of their offspring in response to prevailing environmental circumstances. Such maternal influences (the combined effect of maternal phenotype and maternal genotype; Venturelli et al. 2010) can have pronounced effects on maternal fitness and offspring performance (for recent reviews see Green 2008, Marshall et al. 2008, Uller 2008) and can influence population ecology (Benton et al. 2008, Venturelli et al. 2010). Remarkably, however, factors experienced by females during early development can also affect the phenotypes and fitness of their offspring, as shown in laboratory experiments on hamsters Mesocricetus auratus (Huck et al. 1986), cichlid fish Simochromis pleurospilus (Taborsky 2006), and Drosophila (Vijendravarma et al. 2010). However, there is little evidence that similar long-term effects are found in wild populations.

Manuscript received 20 March 2012; revised 29 August 2012; accepted 11 October 2012. Corresponding Editor: D. E. Schindler.

${ }^{4}$ E-mail: t.burton.1@research.gla.ac.uk
Here we report results from a field experiment investigating maternal influences on offspring arising from variation in both the early growth rate and the adult condition of mothers. Atlantic salmon (Salmo salar) are an appropriate species in which to investigate such effects, due to the contrast in early- and late-life environments experienced in their lifecycle. They spawn in rivers and streams, where juveniles live until smolting (the physiological and morphological preparation for marine life). On becoming smolts, the fish then migrate to sea, where most of their growth occurs. After one or more winters at sea, they return to spawn in fresh water (Klemetsen et al. 2003). The body condition (hereafter, "somatic condition") of adult salmon returning from the sea is a strong indicator of lipid reserves and can vary substantially among individuals, most probably due to conditions experienced at sea (Todd et al. 2008). Variation in the somatic condition of females as they enter fresh water is likely to influence their production of eggs (Todd et al. 2008) and also their somatic condition as they prepare to spawn (from a few weeks to many months later), because the relative lipid content of somatic tissue declines rapidly during the fresh-water migration to the spawning grounds (Jonsson et al. 1997). 
Maternal somatic condition at spawning has been shown in other fish species to influence the number, size, energy content, and survival of offspring (Reznick and Yang 1993, Gagliano and McCormick 2007, Donelson et al. 2009). However, the relevance of somatic condition at spawning time is not necessarily clear, because it might reflect both the state of the fish returning to fresh water and the extent to which soma is converted to gonad (sensu Roff 1992). Reproductive investment is likely influenced by present environmental conditions, but also those experienced by the adults during early development. The transformation into smolts and seaward migration only occurs during spring; fish that fail to smolt remain in fresh water for at least another year (Metcalfe 1998). Thus, the fastest growing fish will smolt a year or more ahead of those that grow at a slower rate. This period of juvenile growth results in a phenotypically plastic response in reproductive investment by adults: Fish that grow relatively slowly as juveniles (i.e., smolt at older ages) produce larger eggs at maturity, even after controlling for body size at the time of spawning (Thorpe et al. 1984, Jonsson et al. 1996). However, these earlier studies did not examine the consequences of these maternal traits for offspring. Using wild Atlantic salmon in their natural environment, we investigated the consequences of variation in the somatic condition, reproductive investment, and early growth of mothers for the growth and survival of their offspring.

\section{Methods}

\section{Selection of maternal fish and crosses}

Atlantic salmon undertaking their spawning migration were captured at the Loch na Croic fish trap on the River Blackwater, Ross Shire, northern Scotland. At the trap site, males and females were held separately in 10 completely dark circular tanks (4 m diameter, $1.5 \mathrm{~m}$ deep), supplied directly with water from the River Blackwater until they reached spawning condition. Within 18 days of their capture, we randomly selected 83 females that were ready to spawn (between 30 November-3 December 2009, determined by netting and lightly squeezing the sides of each fish to detect the presence of loose eggs within the body cavity). The selected females had spent a single winter at sea before returning to fresh water to spawn (one sea winter [1SW] fish), using body size distributions to distinguish 1SW from multi-sea winter (MSW) fish. A sample of scales was collected from each female (for subsequent determination of age at smolting and confirmation of seaage), and their fork length $\left(L_{\mathrm{F}}\right.$, to $\left.0.5 \mathrm{~cm}\right)$ and body mass (to $0.1 \mathrm{~g}$ ) recorded prior to the stripping of their clutch of eggs, which was drained of ovarian fluid and then weighed (to $0.1 \mathrm{~g}$; referred to hereafter as "clutch mass").

Clutch mass was subtracted from body mass to give the somatic mass of each female, which was then used as the measure of female mass in the subsequent calcula- tion of somatic condition because it is not confounded by reproductive mass. We defined somatic condition as somatic mass relative to body length, determined by calculating the residuals of a linear regression (both variables log-transformed) of somatic mass against fork length for all 83 female fish. Given that mature salmon are largely non-feeding during their freshwater spawning migration, our estimate of somatic condition may be influenced by small differences in body mass caused by interindividual variation in the timing of entry into freshwater and/or duration of captivity. Similarly, reproductive investment was defined as the residuals of clutch mass regressed on fork length (both variables logtransformed). Since we were interested in the relative importance of somatic condition and reproductive investment on offspring performance, the subset of 36 clutches used in the field experiment was selected to maximize variation in these traits. We thus excluded "average" condition individuals (i.e., those located closest to the regression lines of somatic mass and clutch mass against fork length) to create four distinct groups of maternal fish (each represented by nine females; size range, $L_{\mathrm{F}} 53.5-62.5 \mathrm{~cm}$, and somatic mass $1079.2-1835.9 \mathrm{~g})$ that differed in their reproductive investment and somatic condition: (1) fish in relatively good somatic condition with high reproductive investment, (2) fish in relatively poor somatic condition with low reproductive investment, (3) fish in good somatic condition with low reproductive investment, and (4) fish in poor somatic condition with high reproductive investment.

A subsample of $\sim 10 \mathrm{~g}$ of eggs from each of the 36 selected clutches was weighed (to $0.01 \mathrm{~g}$ ) and preserved with 5\% buffered formalin (Fleming and $\mathrm{Ng} \mathrm{1987).}$ Fecundity was determined by calculating the number of eggs in each weighed subsample and extrapolating this value to the total clutch mass of each female. Individual eggs from these subsamples were later weighed (to $0.0001 \mathrm{~g}, n=10$ per clutch) to calculate the mean mass of individual eggs (hereafter "egg mass") per female. The remaining eggs from each female were fertilized in vitro with sperm from one of 36 wild anadromous males to create 36 full-sibling families. Adipose fin clips were removed from the parental fish to enable offspring parentage assignment (see Appendix A). Based on body size, all males were assumed to be 1SW fish. The fertilized eggs were transferred to the Scottish and Southern Electricity hatchery at Contin, where they were reared as separate family groups under ambient water temperatures until the eyed stage. Egg mortality was recorded until egg stocking (see Field experiment). When the eggs reached the eyed stage of development, subsamples of $\sim 100$ eggs from each family were transferred to the Marine Scotland freshwater hatchery at Almondbank, Perthshire, Scotland. These subsamples were reared as separate family groups under ambient water temperatures until the onset of independent feeding or "emergence" (when juveniles switch from 
being largely quiescent in the gravel, provisioned with maternal yolk, to active foraging in open water), when 10 per family were preserved in $5 \%$ buffered formalin and later weighed (to $0.0001 \mathrm{~g}$ ) to provide data on juvenile size at emergence. Emergence was defined as the point when $\sim 50 \%$ of the juveniles in each family had completely metabolized their maternal yolk reserves. Emergence occurred between 16 and 20 May 2010 and was measured by an experienced hatchery worker who was not informed of variation in maternal traits.

Scale readings subsequently confirmed that all the selected female spawners were virgin fish that had spent one year at sea (1SW), but varied in their rate of early growth (the number of years they had spent as juveniles in fresh water before turning into smolts and migrating to sea). Those that had grown faster (fast early growth [FEG] females) had reached the size threshold necessary for seaward migration (Metcalfe and Thorpe 1990) earlier, and had become smolts at two years of age, whereas slower growing females had taken three years to reach the smolt stage (slow early growth [SEG] females). Scale samples were also used to back-calculate the body size at smolting of each selected female. These estimates indicated that FEG females smolted at a slightly smaller body size than SEG females, although this difference was not statistically significant (back-calculated $L_{\mathrm{F}} \mathrm{FEG}$ $=12.39 \pm 0.38 \mathrm{~cm}[$ mean $\pm \mathrm{SE}] ; \mathrm{SEG}=13.39 \pm 0.48 \mathrm{~cm}$; $t$ test, $\left.t_{32}=-1.63, P=0.11\right)$. Hence, early growth affects total age at spawning and is also related to size at smolting. We chose to adopt a dichotomous designation of early maternal growth rather than use back-calculated rates of individual growth since growth models for juvenile Atlantic salmon are difficult to fit because they require population-specific adjustments that account for the cessation of feeding for up to six months of the year in freshwater (Elliott and Hurley 1997).

Ideally a factorial mating design, for example where one male is mated with both a FEG and a SEG female, would help separate maternal from paternal influences. However, this was impractical due to constraints imposed by field conditions at the fish trap and issues relating to animal welfare. Given that we were unable to perform a factorial mating design, we chose to focus our study on maternal traits because it is widely acknowledged that the mother has far more influence on offspring performance due to the large discrepancy in size between male and female gametes (Bernardo 1996).

\section{Field experiment}

The growth and survival of offspring from these females were assessed in a tributary (Gleann Mènich) of the River Conon. This mid-altitude stream ( $240 \mathrm{~m}$ above sea level [a.s.1.]) provides suitable habitat for salmon juveniles, but natural spawning is prevented by a barrier to upstream migration of adult fish $(3.5 \mathrm{~km}$ below the experimental site). Both older juvenile salmon that had been stocked as eggs in previous years and a natural population of resident brown trout (all age classes) were present in this stream, which is also open to mammalian and avian predators of juvenile salmon. These conditions provide an ideal setting for investigating maternal effects on offspring that are subject to natural selection pressures. On 22 March 2010, the stream was seeded with eyed-stage eggs from each of the 36 selected females ( $n=1250$ per family, $n=45000$ total). All eggs were first pooled and thoroughly mixed, and then dispersed throughout an $860 \mathrm{~m}$ length of stream in 43 artificial gravel nests that were spaced at intervals of $\sim 20 \mathrm{~m}$ (suitable spawning habitat permitting). This corresponded to a stocking density of $\sim 1050$ eggs per nest (an overall stocking density of $\sim 10 \mathrm{eggs} / \mathrm{m}^{2}$ based on an average stream wet width of $5 \mathrm{~m}$ ). This reflects natural spawning densities for this species (Fleming 1996). No other salmon eggs were stocked in this stream in this year.

During the period 12-14 July 2010 (approximately two months after the hatchery-reared juveniles were estimated to have begun independent feeding, hereafter "emergence"), $400 \mathrm{~m}$ of the stream was electrofished to obtain data on the density and sizes of surviving experimental juveniles. Beginning at the lowest nest site, the stream was notionally divided into $2 \mathrm{~m}$ long sections that were sampled with a single electrofishing pass. All fish (i.e., experimental and older juvenile salmon and brown trout) caught within a section were anesthetized with MS 222. Given the large number of experimental fish captured, it was not practical to measure them accurately in the field and so they were given a lethal dose of anesthetic before being preserved in $100 \%$ ethanol for subsequent measurement of body size and tissue sampling. This design enabled the capture location of all fish to be recorded at a 2-m scale, so that the effect of local density on growth could be estimated (see Data analysis). All preserved experimental fish were subsequently weighed $(0.001 \mathrm{~g})$ and fin-clipped for microsatellite analysis of parentage. Measurements of juveniles preserved in ethanol were converted to estimates of fresh mass by the equation $M_{\mathrm{B} 1}=1.51 M_{\mathrm{B} 2}+70.69$, where $M_{\mathrm{B} 1}$ and $M_{\mathrm{B} 2}$ are fresh and preserved mass values, respectively (see Appendix A for full details of electrofishing, genotyping, and conversion of preserved juvenile mass measurements to estimates of fresh mass).

\section{Data analysis}

We measured the following characteristics of juveniles and their performance: egg size, size at emergence, size at recapture (two months after fry emergence from the gravel), and family-level survival rate of juveniles (i.e., total number recaptured per family). Juvenile fitness in Atlantic salmon can be reliably assessed by monitoring growth and survival soon after emergence from the nest because dispersal is limited and almost invariably there is intense competition and high mortality at this time (Einum et al. 2011a). Not all juveniles were recaptured, for example, because some individuals that failed to secure a feeding territory likely emigrated below the 
TABLE 1. Summary of the optimal linear mixed-effect model explaining variation in mean egg size among female Atlantic salmon (Salmo salar).

\begin{tabular}{lccc}
\hline \hline \multicolumn{1}{c}{ Explanatory variable } & Estimate $\pm \mathrm{SE}$ & $t$ & $P$ \\
\hline Intercept (FEG) & $7.16 \pm 53.23$ & 0.14 & 0.893 \\
Maternal body size & $1.59 \pm 0.92$ & 1.73 & 0.084 \\
Reproductive investment & $83.33 \pm 17.58$ & 4.74 & $<0.0001$ \\
Somatic condition & $-237.84 \pm 82.04$ & -2.90 & $<0.01$ \\
SEG & $-186.81 \pm 85.22$ & -2.19 & $<0.05$ \\
Maternal body size $\times$ SEG & $3.50 \pm 1.50$ & 2.38 & $<0.05$ \\
\hline
\end{tabular}

Notes: The analysis initially controlled for the following maternal traits: body size, reproductive investment, somatic condition, and rate of early growth (slow early growth [SEG] vs. fast early growth [FEG]; see Methods for definitions and details of the analysis). Parameter estimates are given as treatment contrasts with FEG females represented by the intercept. Family was included as a random variable. Reproductive investment refers to the residuals from a regression of $\log (\mathrm{clutch}$ mass) on $\log$ (fork length). Somatic condition refers to the residuals from a regression of log(somatic mass) on $\log$ (fork length).

lowest electrofishing site in the experimental stream. Emigrating juveniles tend to be relatively small or moribund (e.g., Elliott 1990), and those that survived would subsequently grow at locally variable densities that would not be standardized within the experimental design. Hence, our measure of survival is a relative estimate of this trait within the experimental length of the stream (hereafter termed "relative juvenile survival").

To analyze maternal effects on egg size, juvenile size at emergence, and juvenile size when recaptured, we fitted linear mixed-effect (LME) models that incorporated the following maternal traits as a general fixed structure: maternal fork length (hereafter "maternal body size"), reproductive investment, somatic condition, rate of early growth (i.e., FEG or SEG), and (where appropriate) the family's mean value for egg size (hereafter "family egg size"), plus all two-way interactions between these variables. Details of specific models that contained (or omitted) additional explanatory variables are specified in the following paragraphs. Previous research in this catchment has demonstrated that juvenile body size is strongly influenced by the density of conspecifics from the same age class within an upstream distance of $11 \mathrm{~m}$ (Einum et al. 2011b). We were unable to estimate upstream densities on a 1-m scale, so we calculated the numbers of experimental juvenile salmon within $10 \mathrm{~m}$ upstream of a focal individual. Using the same spatial scale, we also calculated upstream densities of older conspecifics and of brown trout, because they could affect the growth of juvenile salmon. These densities were included as additional explanatory variables in the analysis of juvenile size at recapture.

In each LME model, maternal identity was included as a random variable to control for nonindependence of siblings. In the analysis of juvenile size at recapture, the capture location of each individual was included as an additional random factor to control for spatial and temporal correlations among fish that inhabited the same sections of stream and were recaptured on the same day. In the analysis of juvenile size at recapture, measurements of juvenile size and family egg size values were ln-transformed to meet assumptions of normality.

We used generalized linear models (GLMs) with a negative binomial error distribution to analyze variation in maternal fecundity and relative juvenile survival (i.e., as count data). Both GLM's incorporated the explanatory variables in the fixed structure described previously (for further details see Appendix B). See Appendix $\mathrm{B}$ for additional details of the analysis and model selection.

\section{RESULTS \\ Offspring size and number}

Individual egg mass varied more than twofold among families and was positively related to maternal body size and reproductive investment, whereas it was negatively related to somatic condition (Table 1). The largest eggs were thus produced by large females that (for their body length) had the poorest body condition but had heavy ovaries. Egg size was also influenced by a female's age at smolting (and hence presumed rate of early growth; Table 1), with SEG females producing larger eggs than FEG females, despite the two types of female not differing in body size by the time of spawning $\left(L_{\mathrm{F}}\right.$ FEG $=57.94 \pm 0.63 \mathrm{~cm}$ [all results shown as mean $\pm \mathrm{SE}$ ]; $\mathrm{SEG}=57.86 \pm 0.52 \mathrm{~cm} ; t$ test, $\left.t_{32}=0.10, P=0.92\right)$. However, the strength of this effect of a female's early growth on egg size was dependent on her body size at the time of spawning, as indicated by a significant early growth rate $\times$ maternal body size interaction (Table 1 ). Thus, while early growth rate was unrelated to egg size if the females were small by the time of spawning, large SEG spawners produced significantly larger eggs than large FEG spawners (Fig.1).

Fecundity was lower in SEG than FEG females (mean fecundity, FEG $=2406.87 \pm 118.45 ; \mathrm{SEG}=1993.63 \pm$ 115.31, parameter estimate for SEG females in comparison to FEG females, $-0.22 \pm 0.06, z=3.66, P<0.001$ ) and was positively related to reproductive investment (parameter estimate $\pm \mathrm{SE}=1.06 \pm 0.28, z=3.81, P<$ 0.001 ), but unrelated to maternal body size. Family egg size had a strong positive effect on the mass of newly 


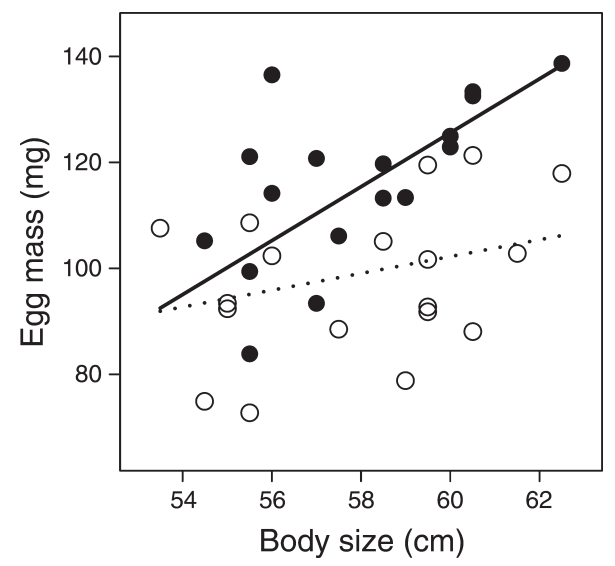

FIG. 1. The relationship between maternal body size and egg mass for female Atlantic salmon (Salmo salar) with fast and slow rates of early growth (FEG, open circles; SEG, solid circles, respectively). The predicted values from the optimal linear mixed-effect (LME) model for FEG and SEG females are represented by the dashed and solid lines, respectively. The predicted values for FEG and SEG females are based on a female of average somatic condition $(-0.002)$ and reproductive investment $(-0.009)$. See Table 1 for analysis.

emerged juveniles and was the only explanatory variable retained in the model describing variation in the size of offspring at this stage of development (parameter estimate $=1.28 \pm 0.10, t=12.54, P<0.0001$; Fig. 2 ); thus, the early growth rate of females did not affect the initial size of their offspring apart from indirectly through its link with egg size.

\section{Offspring performance in natural conditions}

The mean body mass of two-month-old juveniles varied more than twofold among families, ranging from $389.5 \pm 14.8$ to $838.3 \pm 41.1 \mathrm{mg}(n=36$ families, $10-63$ recaptured individuals per family). Size at two months of age was positively related to family egg size, maternal body size, and maternal reproductive investment (Table 2). Local densities of salmon from the same year class and older year classes had positive and negative relationships with juvenile size, respectively, whereas trout density was not significant (Table 2). Even after controlling for other maternal traits and local population densities, there was a link with early maternal growth rate: For a given egg size, SEG mothers produced slower growing offspring than did FEG mothers (Table 2, Fig. 3a). Furthermore, the body size of recaptured juveniles was influenced by significant interactions between family egg size and both maternal body size and reproductive investment (Table 2). Thus, as maternal reproductive investment increased, the difference in subsequent size between juveniles that hatched from large and small eggs diminished (Fig. 3b). Likewise, the discrepancy in size among juveniles from large and small eggs lessened in offspring from larger females (Fig. 3c).
Relative juvenile survival (recapture rate) was highly variable, differing more than sixfold among families despite each female contributing an equal number of eggs to the stream (Fig. 4). In absolute terms, relative juvenile survival was higher for offspring of SEG vs. FEG females $(\mathrm{FEG}=32.94 \pm 2.52, \mathrm{SEG}=38.33 \pm$ 3.45). One family had particularly low survival for its egg size (indicated in Fig. 4a and b). Exclusion of this data point from the analysis removed two previously significant interaction terms from the final model (egg size $\times$ maternal early growth, and maternal body size $\times$ maternal early growth). The remaining terms in the final model were not affected. Thus, for both FEG and SEG females, offspring survival was positively related to family egg size. However, for offspring of FEG females, survival was positively related to maternal somatic condition, whereas a negative relationship was evident between these two traits for SEG females (Table 3, Fig. $4 a, c)$.

\section{Discussion}

Differences in somatic condition, reproductive investment and rate of early growth among mothers exerted a large influence on the size of eggs and, therefore, newlyemerged juveniles. When the surviving juveniles were recaptured after approximately two months in a natural stream environment, substantial variation was present among families in both juvenile body size and relative rates of survival. This occurred despite dividing an equal number of eggs from each female approximately evenly among each of the nests within the experimental stream. Moreover, much of the variation in these traits could be explained by maternal characteristics such as somatic condition, reproductive investment, or rate of early growth, independently of egg size (and in the case of

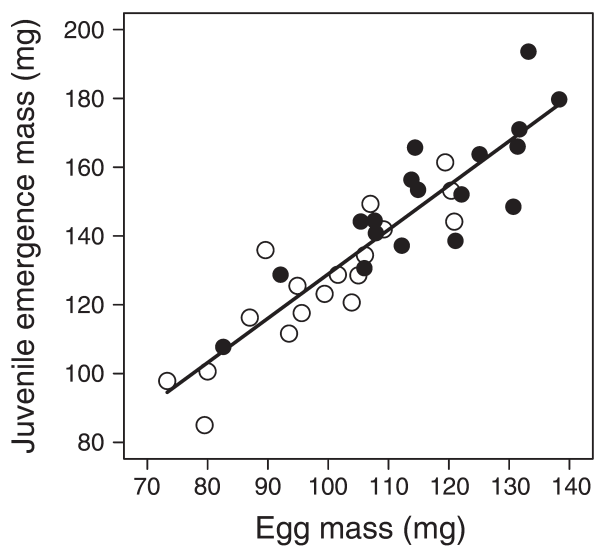

FIG. 2. The relationship between mean egg mass and mean mass of juveniles at the time of emergence. The predicted values from the optimal LME model are represented by the solid line. Data are mean family values and are shown separately for females with fast and slow rates of early growth (FEG, open circles; SEG, solid circles, respectively), although maternal early growth did not influence this relationship. See the Results for analysis. 
TABLE 2. Summary of the optimal linear mixed-effect model explaining variation in mass of juvenile salmon (ln-transformed) recaptured two months after emergence.

\begin{tabular}{lrrc}
\hline \hline \multicolumn{1}{c}{ Explanatory variable } & Estimate $\pm \mathrm{SE}$ & \multicolumn{1}{c}{$t$} & $P$ \\
\hline Intercept (FEG) & $-12.36 \pm 7.28$ & -1.698 & 0.090 \\
Maternal body size & $0.26 \pm 0.12$ & 2.058 & $<0.05$ \\
Reproductive investment & $10.81 \pm 2.83$ & 3.819 & $<0.001$ \\
ln(egg mass) & $4.13 \pm 1.56$ & 2.657 & $<0.01$ \\
SEG & $-0.07 \pm 0.02$ & -2.884 & $<0.01$ \\
Same-age salmon density & $1.82 \times 10^{-3} \pm 3.55 \times 10^{-4}$ & 5.114 & $<0.0001$ \\
Older salmon density & $-2.54 \times 10^{-3} \pm 9.42 \times 10^{-4}$ & -2.692 & $<0.01$ \\
Reproductive investment $\times \ln ($ egg mass) & $-2.36 \pm 0.61$ & -3.842 & $<0.001$ \\
Maternal body size $\times \ln ($ egg mass) & $-0.06 \pm 0.03$ & -2.133 & $<0.05$ \\
\hline
\end{tabular}

Notes: The analysis initially controlled for the same variables listed in Table 1, but included the effects of egg size (mean value per family, ln-transformed) and upstream densities of salmon of the same age, older year class salmon, and trout (see Methods for definitions and details of the analysis). Parameter estimates are given as in Table 1. Family and stream capture location of each individual (recorded at a 2-m scale) were included as crossed random variables.

juvenile body size, important ecological factors such as local densities of conspecifics). Our results also show that maternal influences on offspring size and survival in a natural setting can be complex, as indicated by the influence of interaction terms between various maternal characteristics on each offspring trait that was measured. Overall, the current experiment provides evidence from a natural system that offspring growth and survival in early life is linked to both early maternal growth and the factors that constitute the "current reproductive state" of the mother (i.e., reproductive investment and somatic condition).

Size is of critical importance for early life performance (Kestrel and Munch 2010), with large juveniles being especially favored under adverse conditions (e.g., Einum and Fleming 1999, Dziminski and Roberts 2006, Segers and Taborsky 2011). Accordingly, differences among families in egg size had significant implications because larger eggs resulted in larger juveniles, both at emer- gence and after a period of about two months in natural conditions. Juveniles from larger eggs also had a higher rate of survival than juveniles from small eggs. However, juvenile performance was not determined solely by egg size. Increases in maternal reproductive investment tended to result in larger juveniles for a given egg size. Furthermore, the body mass of juveniles hatching from small eggs was more similar to that of fry from much larger eggs if their mother was either large at the time of spawning or had invested disproportionately in reproductive tissue (see Fig. 3b, c). Indeed, recent research shows that expression levels of the growth hormone receptor (GHR) gene can be higher in juveniles that hatch from small eggs, resulting in a faster rate of growth and similar final body size, when compared to juveniles from large eggs (Segers et al. 2011).

In terms of the maternal phenotype at spawning, females that invested relatively little in reproduction (total clutch mass for a given length) produced smaller
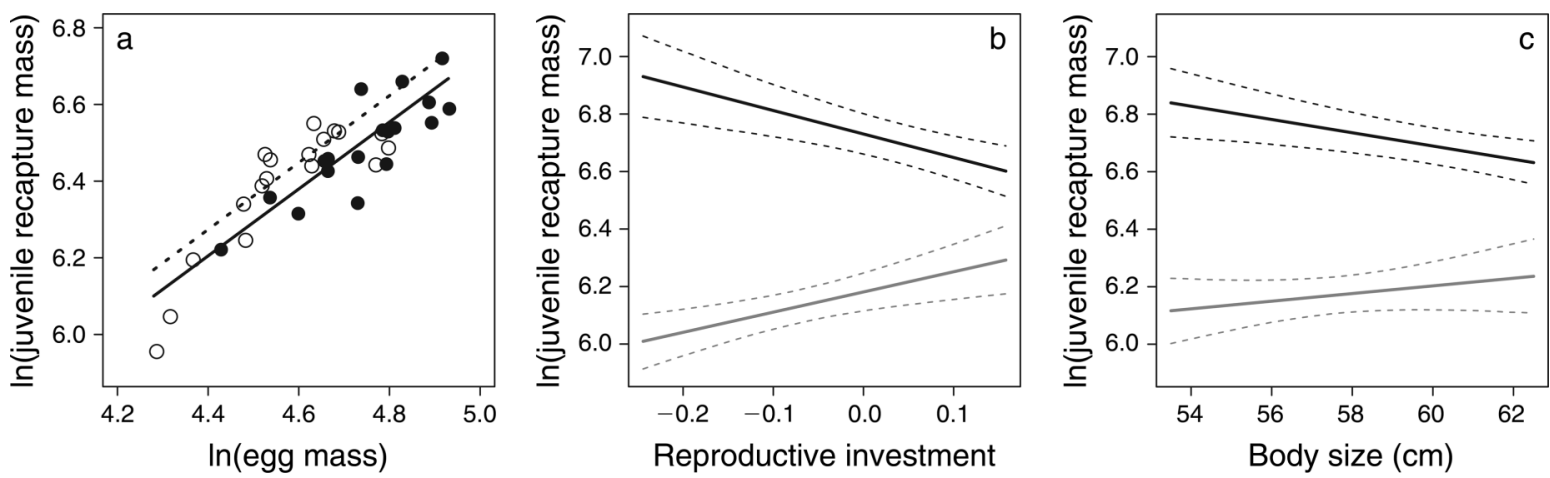

FIG. 3. (a) The relationship between the mean mass of eggs from each family and the mean mass of the resulting juvenile salmon (recaptured two months after emergence). Data and predicted values from the optimal LME model are plotted as in Fig. 1. Both axes are on a logarithmic scale. (b, c) Interactions between maternal reproductive investment and maternal body size, respectively, with egg size. The solid and dashed lines are the predicted values and $95 \%$ confidence intervals from the optimal LME model. Black and gray lines refer to predictions for large $(138 \mathrm{mg})$ and small $(72 \mathrm{mg})$ eggs, respectively. Data points are omitted in panels (b) and (c) to aid visual interpretation. In panels (a) and (b), the predicted values are based on average upstream densities of 46.3 same-age salmon and 12.4 older juvenile salmon, respectively. Additionally, in panel (a) they are based on a female of average body size (fork length $=57.9 \mathrm{~cm}$ ) and reproductive investment $(-0.009)$, in panel $(\mathrm{b})$ they are based on a female of average body size (fork length $=57.9 \mathrm{~cm}$ ), and in panel (c) they are based on a female of average reproductive investment $(-0.009)$. Reproductive investment refers to the residuals from a regression of $\log$ (clutch mass) on $\log$ (fork length). See Table 2 for analysis. 

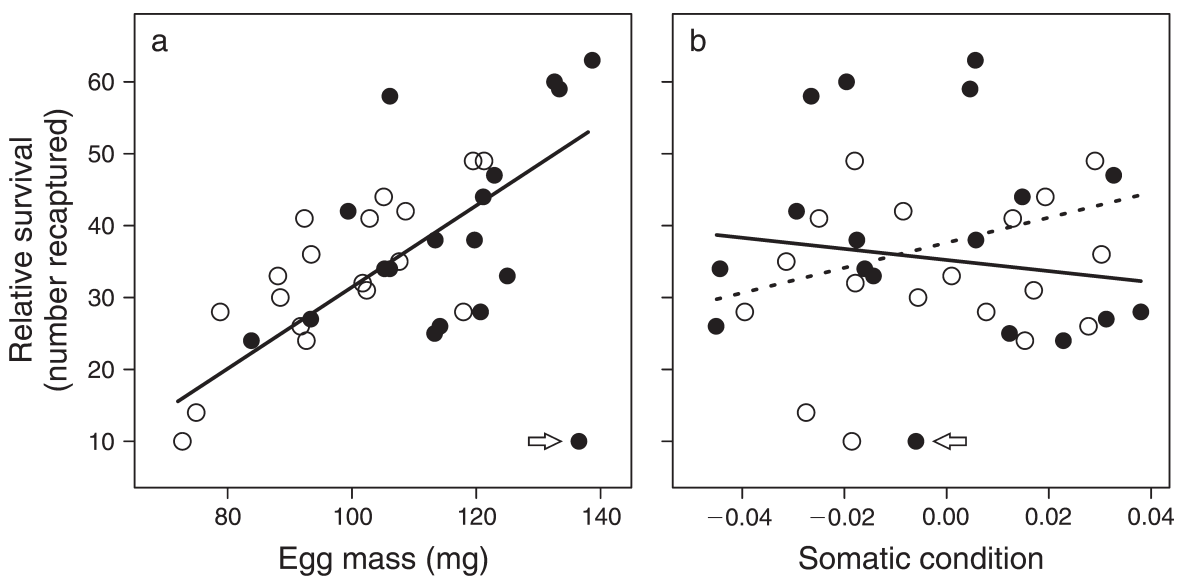

FIG. 4. (a) The relationship between the relative survival rate of juveniles (i.e., number recaptured) and the mean size (mass) of eggs from which they hatched. Data are shown separately for females with fast and slow rates of early growth (FEG, open circles; SEG, solid circles, respectively), although maternal early growth did not influence this relationship. (b) The relationship between relative juvenile survival and maternal somatic condition for mothers with fast and slow rates of early growth (FEG, open circles; SEG, solid circles, respectively). Data and predicted values from the optimal generalized linear model are plotted as in Fig. 1. In panel (a), the predicted values are based on a female of average somatic condition $(-0.002)$, and in panel (b) on a female who produced eggs of average mass $(105.9 \mathrm{mg})$. This analysis does not include data from the family that had particularly low survival for a given egg size (indicated by the arrow in both panels). Somatic condition refers to the residuals from a regression of $\log$ (somatic mass) on $\log$ (fork length). See Table 3 and Results for further details of the analysis.

eggs, had a reduced fecundity, and for a given egg size had smaller offspring. Larger eggs were associated with poor maternal somatic condition, apparently in contrast to some previous studies (e.g., Donelson et al. 2009), but this result may be because the poor somatic condition was a consequence of the investment in eggs. However, the early-life maternal phenotype was also important. Mothers who grew slowly when young (SEG females) tended to produce larger eggs at maturity, as found previously (Thorpe et al. 1984, Jonsson et al. 1996, Taborsky 2006) and these offspring had a higher overall survivorship. Interestingly though, the relationship between somatic condition and the survival of offspring differed among FEG and SEG females. For FEG females, offspring survival was positively related to somatic condition, whereas among SEG mothers a negative relationship was evident. Although the mechanisms underlying this result are unclear, it indicates that offspring survival may be affected by factors that influence the mother both during her early development and later life.

It is also worth noting that we recorded a positive relationship between the upstream density of conspecifics from the same age class and the body size of surviving juveniles, when the inverse of this relationship is generally observed (Einum et al. 2011b). Given the territorial behavior of juvenile salmon, the pattern in our study presumably reflected the patchy habitat structure of the experimental stream because the number of eggs we stocked per nest was similar to that of Einum et al. (2011b). Thus, it is possible that good areas of habitat were able to support high densities of juveniles and also relatively fast individual growth.

Our results collectively suggest that different kinds of offspring (as well as offspring of different size) may be produced by mothers that vary in their current reproductive state and their rate of growth as a juvenile. If this is the case, do such maternal influences constitute an adaptation or a constraint (Marshall and Uller

TABLE 3. Summary of the optimal generalized linear model (negative binomial distribution with Gaussian-link function) explaining variation in relative survival rates of juvenile salmon from different mothers.

\begin{tabular}{lccc}
\hline \hline \multicolumn{1}{c}{ Explanatory variable } & Estimate $\pm \mathrm{SE}$ & $\mathrm{z}$ & $P$ \\
\hline Intercept $(\mathrm{FEG})$ & $-22.51 \pm 8.02$ & -2.807 & 0.005 \\
Somatic condition & $174.65 \pm 79.37$ & 2.201 & $<0.05$ \\
Egg mass & $0.57 \pm 0.08$ & 6.680 & $<0.0001$ \\
SEG & $-2.40 \pm 3.01$ & -0.800 & 0.424 \\
Somatic condition $\times$ SEG & $-251.98 \pm 110.79$ & -2.274 & $<0.05$ \\
\hline
\end{tabular}

Notes: The analysis initially controlled for the same variables listed in Table 1 but included the effects of egg mass (mean value per family). See Methods for details of the analysis. Parameter estimates are given as in Table 1. This analysis does not include data from the family that had particularly low survival for a given egg mass (indicated by the arrows in Fig. 4). 
2007)? Currently, little empirical or theoretical evidence exists with which to evaluate these possibilities in relation to maternal somatic condition and reproductive investment. Links between parental ontogeny and offspring phenotype might enable parents to "program" offspring phenotypes to match the conditions that offspring are likely to encounter in early life (e.g., Bateson et al. 2004). If juvenile and adult ecologies differ, as is the case with Atlantic salmon, cues from conditions experienced by adults in the run up to spawning may be poor predictors of the environment offspring are likely to encounter (Taborsky 2006). Thus, in Atlantic salmon, maternal investment in offspring, whether by nongenetic effects or local adaptation (due to the fact that salmon often home to their natal catchment), may be better determined by a mother's own experience as a juvenile.

FEG and SEG female salmon produce different types of offspring, but these might be suited to different ecological conditions. For example, growth rate in juvenile salmon declines with the altitude of the stream they inhabit: Even within a relatively small altitudinal range; the mean size of one-year-old fish can decline by over $33 \%$ with an increase in altitude of only $270 \mathrm{~m}$ (Egglishaw and Shackley 1985, Baum et al. 2004). Highaltitude tributaries are known to produce a higher proportion of SEG fish (Shearer 1992), presumably because a minimum size threshold must be reached before juveniles migrate to the sea (Metcalfe and Thorpe 1990). Thus, it is possible that FEG females are more likely to originate from lower altitude, more food-rich tributaries, while SEG females are more likely to come from higher altitude streams with poorer growth opportunities. Given such differences in early growth performance, it is possible that FEG and SEG females are producing eggs/offspring that are suited to these different niches. Indeed, female salmon who spawn in upland sites tend to produce fewer but larger eggs (for a given body size) than females that spawn in lowland sites (Bacon et al. 2012). Larger eggs result in larger juveniles which outperform individuals from smaller eggs, particularly in food-poor (e.g., colder/oligotrophic upland) environments (Einum and Fleming 1999). Alternatively, it is possible that mothers who developed slowly as juveniles may be low-quality individuals, that then produce lower quality offspring (Monaghan 2008).

It is also worth acknowledging that the current study only considers one component of maternal fitness: offspring survival and growth in fresh water. However, maternal fitness is influenced at other stages of the life cycle. For example, although SEG juveniles smolt later than faster growing females, they tend to do so at a larger body size (Økland et al. 1993). In Atlantic salmon, smolt size within a cohort is related positively to ocean survival (Salminen et al. 1995, Saloniemi et al. 2004). Thus, a larger size at smolting (and higher survival probability at sea) might offset (to an extent) the cost of delayed seaward migration and likely greater instream mortality. Furthermore, in terms of lifetime reproductive success, recent evidence demonstrates that mothers can mitigate the effects of poor growth during early development by adjusting allocation to growth and reproduction in adulthood, regardless of the quality of the adult environment (Auer 2010).

It is not possible to investigate these possibilities with the current experiment as it only considers early offspring performance and was conducted in a relatively homogeneous environment: All eggs were stocked at a uniform density into a single section of a mid-altitude stream. Further research is needed where the effects of maternal reproductive investment, somatic condition, and juvenile growth rate are disentangled experimentally and the growth and survival of offspring then evaluated under a range of environmental conditions.

\section{ACKNOWLEDGMENTS}

We thank Scottish and Southern Electricity for use of the Contin hatchery, L. Brydon for help with the parental crosses, and M. S. Miles at Almondbank hatchery for assistance with fish husbandry. We are grateful for the assistance provided by $\mathrm{J}$. Henry, M. Wyndham, A. McKelvey, J. Orpwood, and M. Norris in field work, and J. Henry in reading scales. We thank the landowners for permission to work on their property and $\mathbf{J}$. Mota-Velasco at Landcatch Natural Selection Ltd. for carrying out the genotyping. We also thank two anonymous referees for excellent comments on an earlier version of the manuscript. This project was funded by a NERC small grant to N. B. Metcalfe, J. D. Armstrong, and S. McKelvey, and a FSBI small grant to T. Burton, who was supported by a University of Glasgow Postgraduate Scholarship and an ORSAS award. The experiment was authorized by licenses from the U.K. Home Office.

\section{Literature Cited}

Auer, S. K. 2010. Phenotypic plasticity in adult life-history strategies compensates for a poor start in life in Trinidadian guppies Poecilia reticulata. American Naturalist 176:818829.

Bacon, P. J., J. C. Maclean, I. A. Malcolm, and W. S. C. Gurney. 2012. Ova fecundity in Scottish Atlantic salmon Salmo salar: predictions, selective forces and causal mechanisms. Journal of Fish Biology 81:921-938.

Bateson, P., et al. 2004. Developmental plasticity and human health. Nature 430:419-421.

Baum, D., R. Laughton, J. D. Armstrong, and N. B. Metcalfe. 2004. Altitudinal variation in the relationship between growth and maturation in salmon parr. Journal of Animal Ecology 73:253-260.

Benton, T. G., J. J. H. St Clair, and S. J. Plaistow. 2008. Maternal effects mediated by maternal age: from life histories to population dynamics. Journal of Animal Ecology 77:1038-1046.

Bernardo, J. 1996. Maternal effects in animal ecology. American Zoologist 36:83-105.

Donelson, J. M., P. L. Munday, and M. I. McCormick. 2009. Parental effects on offspring life histories: when are they important? Biology Letters 5:262-265.

Dziminski, M. A., and J. D. Roberts. 2006. Fitness consequences of variable maternal provisioning in quacking frogs (Crinia georgiana). Journal of Evolutionary Biology 19:144155.

Egglishaw, H. J., and P. E. Shackley. 1985. Factors governing the production of juvenile Atlantic salmon in Scottish streams. Journal of Fish Biology 27A:27-33. 
Einum, S., A. G. Finstad, G. Robertsen, K. H. Nislow, S. McKelvey, and J. D. Armstrong. 2011a. Natal movement in Atlantic salmon: a body size-dependent strategy? Population Ecology 54:285-294.

Einum, S., and I. A. Fleming. 1999. Maternal effects of egg size in brown trout (Salmo trutta): norms of reaction to environmental quality. Proceedings of the Royal Society of London B 266:2095-2100.

Einum, S., G. Robertsen, K. H. Nislow, S. McKelvey, and J. D. Armstrong. 2011b. The spatial scale of density-dependent growth and implications for dispersal from nests in juvenile Atlantic salmon. Oecologia 165:959-969.

Elliott, J. M. 1990. Mechanisms responsible for population regulation in young migratory trout, Salmo trutta. II. Fish growth and size variation. Journal of Animal Ecology 59:171-185.

Elliott, J. M., and M. A. Hurley. 1997. A functional model for maximum growth of Atlantic salmon parr, Salmo salar, from two populations in northwest England. Functional Ecology 11:592-603.

Fleming, I. A. 1996. Reproductive strategies of Atlantic salmon: Ecology and evolution. Reviews in Fish Biology and Fisheries 6:379-416.

Fleming, I. A., and S. Ng. 1987. Evaluation of techniques for fixing, preserving, and measuring salmon eggs. Canadian Journal of Fisheries and Aquatic Sciences 44:1957-1962.

Gagliano, M., and M. I. McCormick. 2007. Maternal condition influences phenotypic selection on offspring. Journal of Animal Ecology 76:174-182.

Green, B. S. 2008. Maternal effects in fish populations. Advances in Marine Biology 54:1-105.

Huck, U. W., J. B. Labov, and R. D. Lisk. 1986. Food restricting young hamsters (Mesocricetus auratus) affects sex ratio and growth of subsequent offspring. Biology of Reproduction 35:592-598.

Jonsson, N., B. Jonsson, and I. A. Fleming. 1996. Does early growth cause a phenotypically plastic response in egg production of Atlantic salmon? Functional Ecology 10:8996.

Jonsson, N., B. Jonsson, and L. P. Hansen. 1997. Changes in proximate composition and estimates of energetic costs during upstream migration and spawning in Atlantic salmon Salmo salar. Journal of Animal Ecology 66:425-436.

Kestrel, P. O., and S. B. Munch. 2010. Extreme selection on size in the early lives of fish. Evolution 64:2450-2457.

Klemetsen, A., P. A. Amundsen, J. B. Dempson, B. Jonsson, N. Jonsson, M. F. O'Connell, and E. Mortensen. 2003. Atlantic salmon Salmo salar L., brown trout Salmo trutta L. and Arctic charr Salvelinus alpinus (L.): a review of aspects of their life histories. Ecology of Freshwater Fish 12:1-59.

Marshall, D. J., R. M. Allen, and A. J. Crean. 2008. The ecological and evolutionary importance of maternal effects in the sea. Oceanography and Marine Biology: An Annual Review 46:203-250.

Marshall, D. J., and T. Uller. 2007. When is a maternal effect adaptive? Oikos 116:1957-1963.

Metcalfe, N. B. 1998. The interaction between behavior and physiology in determining life history patterns in Atlantic salmon (Salmo salar). Canadian Journal of Fisheries and Aquatic Sciences 55:93-103.

Metcalfe, N. B., and J. E. Thorpe. 1990. Determinants of geographical variation in the age of seaward-migrating Salmon, Salmo salar. Journal of Animal Ecology 59:135-145.

Monaghan, P. 2008. Early growth conditions, phenotypic development and environmental change. Philosophical Transactions of the Royal Society of London B 363:16351645.

Økland, F., B. Jonsson, A. J. Jensen, and L. P. Hansen. 1993. Is there a threshold size regulating seaward migration of brown trout and Atlantic salmon? Journal of Fish Biology 42:541550.

Reznick, D., and A. P. Yang. 1993. The influence of fluctuating resources on life history: Patterns of allocation and plasticity in female guppies. Ecology 74:2011-2019.

Roff, D. A. 1992. The evolution of life histories: theory and analysis. Chapman and Hall, New York, New York, USA.

Salminen, M., S. Kuikka, and E. Erkamo. 1995. Annual variability in the survival of sea-ranched Baltic salmon, Salmo salar L.: significance of smolt size and marine conditions. Fisheries Management and Ecology 2:171-184.

Saloniemi, I., E. Jokikokko, I. Kallio-Nyberg, E. Jutila, and P. Pasanen. 2004. Survival of reared and wild Atlantic salmon smolts: size matters more in bad years. ICES Journal of Marine Science 61:782-787.

Segers, F. H. I. D., G. Berishvili, and B. Taborsky. 2011. Egg size-dependent expression of growth hormone receptor accompanies compensatory growth in fish. Proceedings of the Royal Society B 279:592-600.

Segers, F. H. I. D., and B. Taborsky. 2011. Egg size and food abundance interactively affect juvenile growth and behaviour. Functional Ecology 25:166-176.

Shearer, W. M. 1992. The Atlantic salmon: natural history, exploitation and future management. Fishing News Books, Oxford, UK.

Taborsky, B. 2006. Mothers determine offspring size in response to own juvenile growth conditions. Biology Letters 2:225-228.

Thorpe, J. E., M. S. Miles, and D. S. Keay. 1984. Developmental rate, fecundity and egg size in Atlantic salmon, Salmo salar L. Aquaculture 43:289-305.

Todd, C. D., S. L. Hughes, C. T. Marshall, J. C. Maclean, M. E. Lonergan, and E. M. Biuw. 2008. Detrimental effects of recent ocean surface warming on growth condition of Atlantic salmon. Global Change Biology 14:958-970.

Uller, T. 2008. Developmental plasticity and the evolution of parental effects. Trends in Ecology and Evolution 23:432438.

Venturelli, P. A., C. A. Murphy, B. J. Shuter, T. A. Johnston, P. J. van Coeverden de Groot, P. T. Boag, J. M. Casselman, R. Montgomerie, M. D. Wiegand, and W. C. Leggett. 2010. Maternal influences on population dynamics: evidence from an exploited freshwater fish. Ecology 91:2003-2012.

Vijendravarma, R. K., S. Narasimha, and T. J. Kawecki. 2010. Effects of parental larval diet on egg size and offspring traits in Drosophila. Biology Letters 6:238-241.

\section{Supplemental Material}

\section{Appendix A}

Details of selection of broodstock, electrofishing, genotyping, and conversion of preserved juvenile mass measurements into estimates of fresh mass (Ecological Archives E094-054-A1). 